\title{
PENGARUH PENGGUNAAN ASPAL BUTON B5/20 DENGAN AGREGAT LOKAL MADURA PADA CAMPURAN ASPAL PANAS AC-WC TERHADAP KARAKTERISTIK MARSHALL
}

\author{
Ahmad Fatoni ${ }^{1}$ dan Nurul Afandi ${ }^{2}$ \\ ${ }^{1}$ Program Studi Teknik Sipil, Fakultas Teknik, Universitas Madura, Pamekasan \\ E-mail: Nufanafandi96@gmail.com
}

\begin{abstract}
ABSTRAK: Perkerasan lentur umumnya menggunakan aspal minyak sebagai perekatnya dan beberapa bahan tambah untuk meningkatkan kinerja campurannya. Asbuton dapat dijadikan suatu bahan tambah yang dapat mengurangi kebutuhan aspal minyak dalam suatu campuran dan sekaligus dapat meningkatkan performa campuran sehingga tidak dibutuhkan lagi penambahan zat additif dan sebagainya. Asbuton ini merupakan jenis aspal alam yang jumlahnya melimpah terdapat di pulau Buton, Sulawesi Tenggara, Indonesia. Produk Asbuton yang saat ini tengah banyak dikembangkan adalah Asbuton jenis BGA (Buton Granular Asphalt). Material ini memiliki kadar bitumen 20-25\% dari beratnya dan telah digunakan di beberapa lokasi namun belum maksimal penggunaanya. Penelitian ini untuk mengetahui nilai karakteristik marshall yang di lihat dari nilai stabilitas, flow, VIM, VMA, VFB, serat marshall quotient (MQ), kadar Asbuton yang di gunakan adalah 0\%, 2\%, 2,5\%, 3\% dengan penggunaa agregat Rek Kerrek. Dari Hasil Pengujian didapatkan campuran yang memenuhi persyaratan yaitu kadar Asbuton B5/20 3\% penggunaan Aspal 5,2\% dengan nilai density sebesar 2,2012 dan nilai stabilitas sebesar 1540,00. Dari hasil uji marshall juga dapat di simpulkan bahwa penggunaan Asbuton B5/20 dengan agregat Lokal Madura berpengaruh terhadap nilai karakteristik marshall dan mencapai campuran optimum pada campuran dengan Asbuton B5/20 3\% penggunaan Aspal 5,2\%.
\end{abstract}

Kata kunci: Asbuton B5/20, Agregat, Karakteristik Marshall, Density

\section{PENDAHULUAN}

Penggunaan aspal panas (asphalt hot mix) pada dunia konstruksi semakin meningkat karena setiap tahunnya pekerjaan peningkatan ataupun pembangunan jalan baru semakin meningkat. Salah satu jenis aspal panas yang sering digunakan yaitu AC-WC (Asphalt Concrete Wearing Course), AC-WC merupakan lapis aspal beton yang berfungsi sebagai lapisan aus pada sebuah konstruksi perkerasan jalan. Di madura pada umumnya produksi aspal panas menggunakan material aspal produksi PT.Pertamina dan agregat beraspal dari luar madura sehingga mengakibatkan biaya produksi yang besar dan berpengaruh terhadap kapasitas beban pekerja jalan yang ada di dalam jaringan nasional dan propinsi di pulau Madura. Oleh karena itu perlu adanya efisiensi dan inovasi penyusun material campuran aspal panas mengingat dari segi kuantitas material lokal yang ada di Madura jumlahnya yang cukup banyak serta penggunaan material yang bersifat alami. Salah satu sumber kekayaan alam Indonesia yang cukup potensial adalah aspal alam yang terletak di pulau buton Sulawesi Tenggara di sebut asbuton. Aspal alam yang tersedia di pulau buton mempunyai cadangan yang sangat besar yang merupakan deposit aspal alam terbesar di dunia. Menurut Bidang wilayah pertambangan dan energi provinsi Sulawesi tenggara serta data satelit memperlihatkan cadangan aspal alam total adalah sekitar 677,247 juta ton (Setiawan A, 2011), sehingga dengan kebutuhan material yang banyak tidak menjadi ketergantungan pada perusahaan tertentu.

Inovasi yang bisa dilakukan yaitu menggunakan aspal buton yang merupakan aspal alam dan batu pecah lokal Madura sebagai agregat pada campuran aspal panas. Dengan jumlah yang sangat memadai batu pecah lokal madura pada saat ini hanya digunakan pada pekerjaan jalan lapis penetrasi (lapen), padahal berdasarkan pada penelitian yang dilakukan oleh Setiawan ,A.(2017) yang menjadikan batu lokal madura sebagai agregat pada campuran aspal panas AC-WC dengan penggunaan filler batu kapur memberikan peningkatan pada uji marshall. Sehingga perlu adanya pengembangan dalam pemanfaatan batu lokal Madura sebagai material dalam pembuatan aspal panas (hot mix) dengan variasi yang berbeda.

\section{METODOLOGI PENELITIAN}

Alur penelitian tedapat pada Gambar 1 berikut.

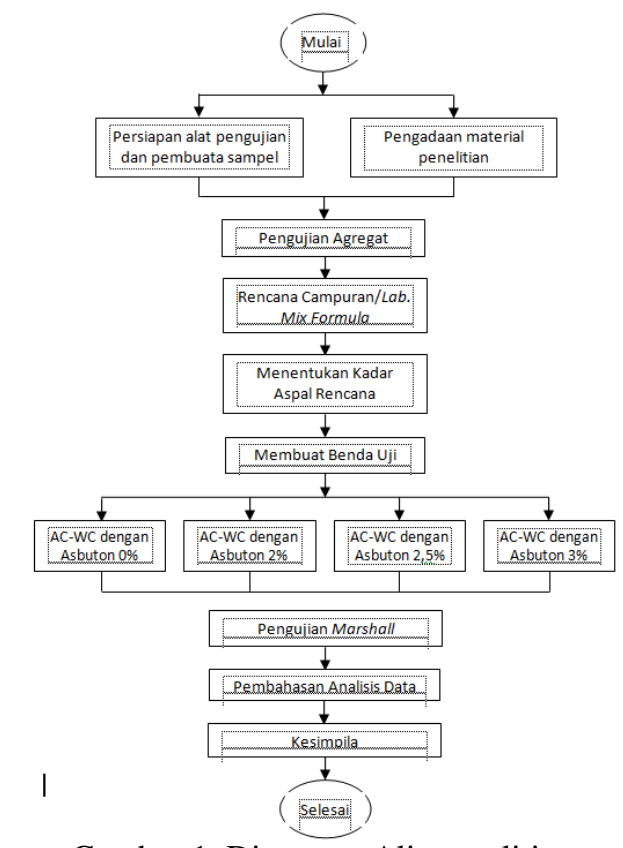

Gambar 1. Diagaram Alir penelitian

\section{1) Jenis dan Lokasi Penelitian}

Jenis penelitian ini merupakan penelitian eksperimen. Adapun laboratorium yang digunakan ialah laboratorium Dua Putri Kedaton dan Laboratorium Teknik Sipil 
Universitas MAdura, untuk melaksanakan pengujian propertis aspal dan pembuatan benda uji Marshall, pengujian Marshall, pengujian propertis BGA Tipe B5/20, dan pengujian propertis agregat dilaksanakan di laboratorium milik PT. Rapi Arjasa.

\section{2) Pengumpulan Data}

Data yang dikumpulkan didapat dari hasil uji eksperimen dengan kondisi laboratorium yang terdiri dari beberapa tahapan yaitu Tahap Pemeriksaan Material yang terdiri dari Pemeriksaan bahan unsur penyusun campuran aspal beton (Aggregat, Aspal, Filler, AntiStripping Agent) dan pemeriksaan material Buton Granular Asphalt kemudian dilanjutkan Tahap Perancangan Benda uji, Tahap Persiapan dan pembuatan benda uji Marshall, dan Tahap Uji Marshall Sebelum KAO dan Sesudah KAO.

\section{3) Pengolahan Data}

Data-data yang diperoleh dari hasil uji eksperimen dengan kondisi laboratorium dinput serta diproses kedalam program Microsoft Excel dan kemudian disajikan dalam bentuk tabel dan grafik. Grafik disajikan dengan menampilkan perbandingan hasil uji per parameter Marshall untuk dapat menunjukan perbedaan pengaruhnya.

\section{HASIL PENGUJIAN DAN ANALISA \\ 1) Hasil pengujian material \\ - Pengujian keausan}

Pengujian keausan/abrasi di lakukan di Laboratorium Teknik Sipil Universitas Madura dengan hasil keausan 27,34\%. Maka memenuhi syarat Spesifikasi Bina Marga 2018 revisi 2 yaitu maksimal $30 \%$.

\section{- Pengujian filler}

Penggunaan filler semen Gersik atau bahan pengisi dilakukan pengujian sesuai persyaratan yang terdapat pada Spesifikasi Umum Bina Marga 2018 revisi 2 yaitu pengujian Gradasi.

- Pengujian Analisa Saringan

Pada pengujian analisa saringan di ambil berat contoh masing-masing 500 gram dengan dua kali pengujian gradasi dan mendapatkan hasil lolos saringan no. 200 rata-rata 95,90 yang terdapat pada Gambar 2. Berdasarkan hasil pengujian tersebut maka persyaratan analisa saringan berdasarkan Spesifikasi Umum Bina Marga 2018 yang mengharuskan lolos saringan No. 200 Minimal $75 \%$.

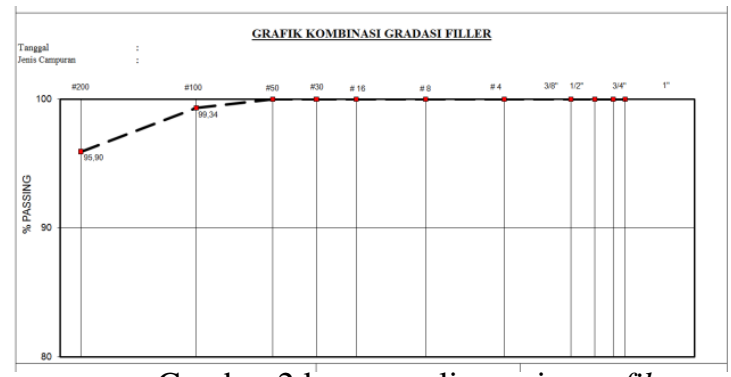

Gambar 2 kurva analisa saringan filer

\section{- Pengujian asbuton}

Penggunaan Asbuton B5/20 dilakukan pengujian sesuai persyaratan yang terdapat pada Spesifikasi Umum Bina Marga 2018 revisi 2 yaitu pengujian Gradasi

- Pengujian Analisa Saringan

Pada pengujian analisa saringan di ambil berat contoh masing-masing 500 gram dengan dua kali maka di simpulkan bahwa asbuton B5/20 ini memenuhi persyaratan untuk di gunakan pada campuran aspal panas merujuk pada Gambar 3 yaitu asbuton tertahan saringan No. 8 sebesar $100 \%$ sedangkan pada pengujian di dapat $100 \%$.

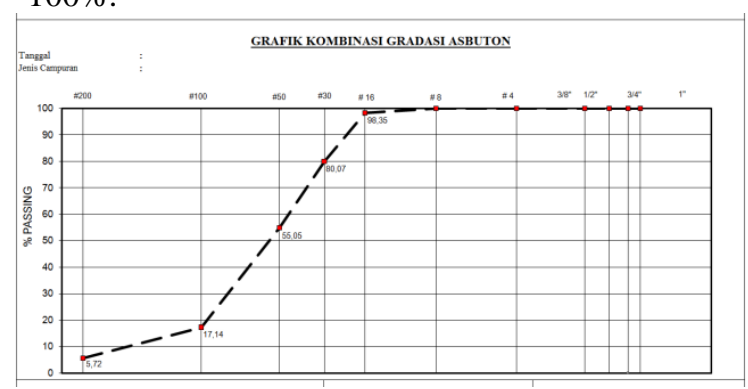

Gambar kurva analisa saringan Asbuton B5/20

\section{2) Menentukan kadar aspal rencana campuran}

Untuk mengetahui kadar aspal rencana maka menggunakan hasil pengujian analisa saringan yang telah di lakukan pada masing-masih agregat. dan di dapat nilai kadar aspal rencana adalah 5,2 \% dengan penggunaan Filler $1 \%$.

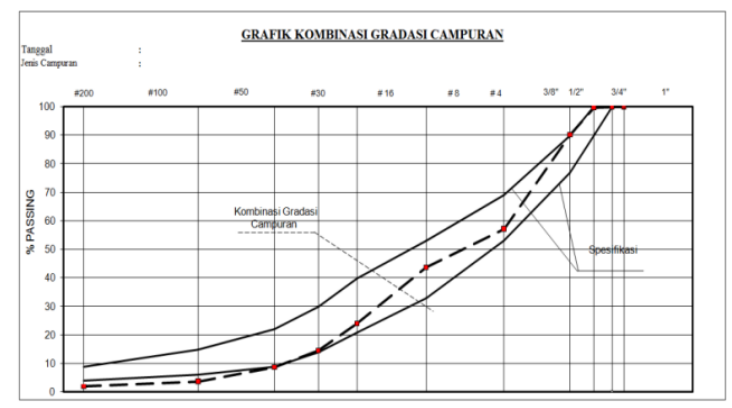

Gambar 3 Kurva Analisa Saringan Campuran 3) Hasil pengujian benda uji (Sampel)

Hasil pengujian yang di lakukan melalui beberapa tahap yaitu. Berat jenis bulk dari total aggregate aspal $5,7 \%$ dan Asbuton 2,5\% adalah 2,475, berat jenis semu $2,570 \mathrm{gr} / \mathrm{cm}^{3}$, berat jenis efektif 2,523, berat jenis maksimum campuran 2,336, penyerapan aspal 0,792\%, kepadatan benda uji density 2,278, stabilitas 116, flow 2,80 , VIM $2,28 \%$, VMA $13,21 \%$, VFB $82,74 \%$, dan MQ $540,71 \mathrm{~kg} / \mathrm{mm}$

Hasil perhitungan campuran aspal dengan alat marshall secara lengkap terdapat pada Tabel 1 dan Gambar 4 sampai Gambar 9 di bawah ini . 
Tabel 1 Hasil Pengujian Marshall

\begin{tabular}{|c|c|c|c|c|c|c|c|c|}
\hline No & Aspal & Asbuton & $\begin{array}{c}\text { Stabilitas } \\
(\mathbf{K g})\end{array}$ & $\begin{array}{l}\text { Flow } \\
(\mathrm{mm})\end{array}$ & $\begin{array}{l}\text { VIM } \\
(\%)\end{array}$ & $\begin{array}{c}\text { VMA } \\
(\%)\end{array}$ & $\begin{array}{l}\text { VFB } \\
(\%)\end{array}$ & $\begin{array}{c}\text { Marshall } \\
\text { Quotion } \\
(\mathrm{Kg} / \mathrm{mm})\end{array}$ \\
\hline \multirow{4}{*}{1} & \multirow{4}{*}{$4,70 \%$} & $0 \%$ & 835,00 & 2,4 & 9,21 & 16,96 & 45,76 & 347,92 \\
\hline & & $2,00 \%$ & 1240,00 & 2,5 & 6,83 & 14,66 & 53,39 & 496,00 \\
\hline & & $2,50 \%$ & 1449,00 & 3,1 & 5,61 & 13,5 & 58,47 & 467,42 \\
\hline & & $3,00 \%$ & 1527,00 & 3,0 & 6,07 & 13,88 & 58,29 & 509,00 \\
\hline & & & & & & & & \\
\hline \multirow{4}{*}{2} & \multirow{4}{*}{$5,20 \%$} & $0 \%$ & 1018,00 & 2,8 & 9,07 & 17,85 & 49,18 & 363,57 \\
\hline & & $2,00 \%$ & 1423,00 & 2,4 & 3,22 & 12,39 & 73,98 & 592,92 \\
\hline & & $2,50 \%$ & 1579,00 & 2,7 & 5,46 & 14,37 & 62,03 & 584,81 \\
\hline & & $3,00 \%$ & 1540,00 & 2,8 & 3,04 & 12,14 & 74,93 & 550,00 \\
\hline & & & & & & & & \\
\hline \multirow{4}{*}{3} & \multirow{4}{*}{$5,70 \%$} & $0 \%$ & 1122,00 & 3,5 & 8,39 & 18,32 & 53,96 & 320,57 \\
\hline & & $2,00 \%$ & 1279,00 & 2,6 & 3,48 & 13,64 & 74,50 & 491,92 \\
\hline & & $2,50 \%$ & 1514,00 & 2,8 & 1,55 & 11,86 & 86,95 & 540,71 \\
\hline & & $3,00 \%$ & 1553,00 & 3,5 & 2,27 & 12,46 & 81,77 & 443,71 \\
\hline
\end{tabular}

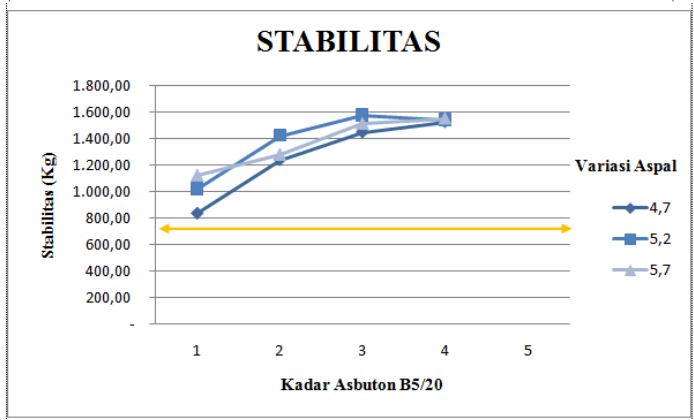

Gambar 4. Kurva Hubungan Stabilitas dengan Kadar Asbuton B5/20

Berdasar Gambar 4 didapat kurva dengan hasil nilai stabilitas pada variasi aspal yang dipakai maka didapat hasil dari ketiga variasi aspal memenuhi batas minimal nilai stabilitas yaitu minimal $800 \mathrm{Kg}$.

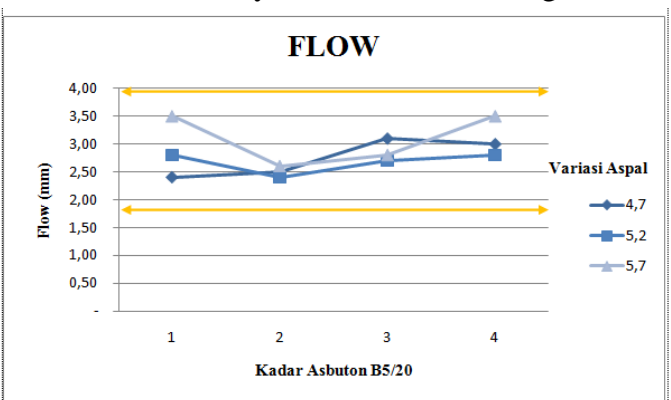

Gambar 5. Kurva Hubungan Flow dengan Kadar Asbuton $\mathrm{B} 5 / 20$

Dari hasil Gambar 5 pada penggunaan variasi aspal 4,7, 5,2 dan 5,7 mendapatkan hasil pada pengujian Flow memenuhi syarat yaitu berada diantar 2 sampai $4 \mathrm{~mm}$.

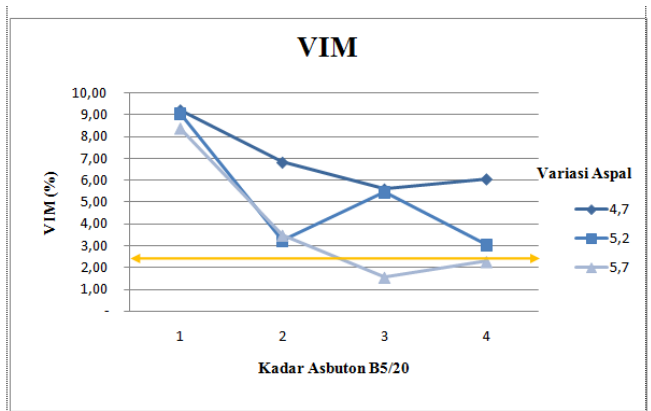

Gambar 6. Kurva Hubungan VIM (Void In Mix) dengan Kadar Asbuton B5/20
Berdasarkan pada Gambar 6 didapat nilai VIM pada penggunaan kadar asbuton 3\% tidak memenuhi syarat, sedangkan penggunaan kadar asbuton lainnya memenuhi syarat sesuai Spesifikasi Bina Marga 2018 Revisi 2.

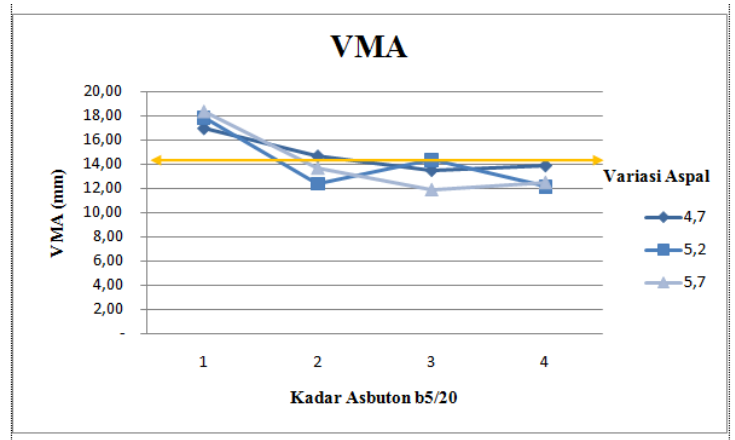

Gambar 7 Kurva Hubungan VMA (Void In Mineral Agregat) dengan Kadar Asbuton B5/20

Pada Gambar 7 didapat nilai VIM yang memenuhi persyaratan sesuai dengan Spesifikasi Umum Bina Marga 2018 Revisi 2 yaitu pada nilai kadar asbuton $1 \%$.

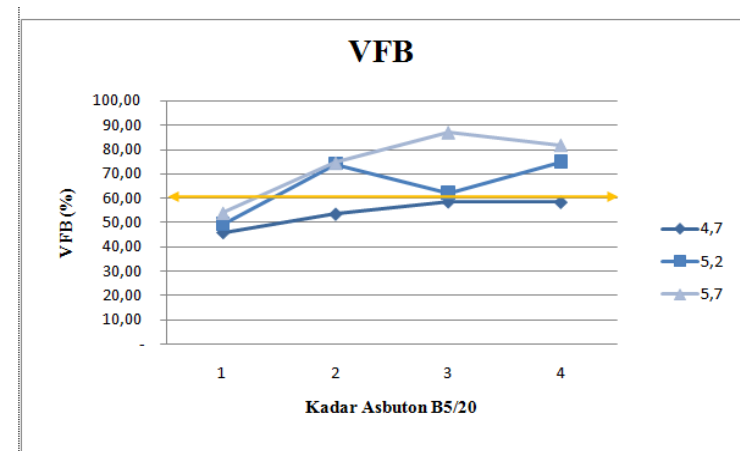

Gambar 8. Kurva Hubungan VFB/ Rongga Udara Terisi Aspal dengan Kadar Asbuton B5/20

Pada Gambar 8 didapat nilai VFB yang memenuhi persyaratan sesuai dengan Spesifikasi Umum Bina Marga 2018 Revisi 2 yaitu pada nilai kadar asbuton $2 \%$ dengan kadar aspal 5,2 dan 5,7, kadar asbuton 3\% dengan kadar aspal 5,2\% dan 5,7\% serta pada penggunaan asbuton sebesar 4\% pada kadar aspal 5,2 dan 5,7.

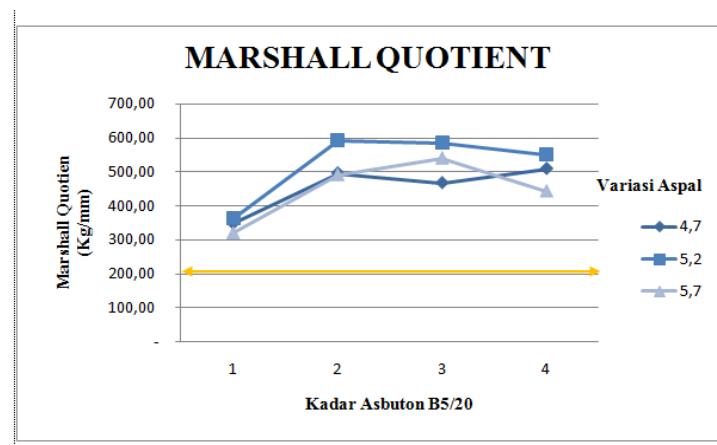

Gambar 9. Kurva Hubünan M̄Q (Marshāll Quotient) dengan Kadar Asbuton B5/20

Berdasar Gambar 9 didapat kurva dengan hasil nilai stabilitas pada variasi aspal yang dipakai maka didapat hasil dari ketiga variasi aspal memenuhi batas minimal nilai Marshall Quotient. 


\section{KESIMPULAN}

Dari hasil penelitian yang telah dilakukan, dapat di tarik kesimpulan sebagai berikut.

1. Penggunaan Asbuton B5/20 sebagai bahan tambah dengan menggunakan agregat dari Desa Rek-Kerrek Dapat mempengaruhi pada nilai karakteristik marshall setiap penambahan Asbuton B5/20 pada penggunaan aspal optimum dari masing masing variasi.

2. Yang dapat memenuhi persyaratan Spesifikasi Bina Marga 2018 revisi 1 terhadap karakteristik Marshall yaitu Aspal 5,2\% dengan variasi Asbuton B5/20 2\% da 3\%, serta Aspal 5,7\% dengan Variasi Asbuton B5/20 2\%. Namun dari 3 jenis campuran tersebut dapat di simpulkan campuran optimum yaitu penggunaan Aspal 5,2\% dengan Variasi Asbuton B5/20 3\% Karna yang memenuhi Spesifikasi Bina Marga 2018 revisi 1 dengan nilai Stabilitas $1553 \mathrm{Kg}$.

3. Dari hasil pengujian maka dapat di simpulkan campuran optimum yaitu penggunaan Asbuton B5/20 $3 \%$ dengan Aspal 5,2\% dengan nilai VIM 3,04, VMA 12,14, VFB 74,93, MQ 550,00 dengan nilai density 2,2443 .

\section{SARAN}

Dari hasil penelitian yang sudah di lakukan disarankan:

1) Penelitian lanjutan pengguanaan Asbuton $B 5 / 20$ dapat di pertimbangkan untuk di gunakan sebagai bahan aditif (modifier)pada campuran beraspal ACWC, dengan tujuan campuran beraspal AC-WC memiliki stabilitas yang lebih tinggi.

2) Pengujian analisa saringan harus di perbaiki agar mendapatkan campuran yang lebih baik.

3) Penelitian lebih lanjut dengan penggunaan Asbuton B5/20 dengan Agregat Lokal serta Filler yang berbeda supaya mendapatkan hasil yang lebih baik serta meningkatkan nilai ekonomis.

\section{DAFTAR PUSTAKA}

Batubara, MI, Zulkarnain A, Muis, Lubis, AS Studi Pengaruh Penambahan Buton Granular Asphalt 5/20 Terhadap Karasteristik Marshall Campuran Aspal Panas AC-WC. Departemen Teknik Sipil, Universitas Sumatra.

Kementrian Pekerjaan Umum Dan Penataan Ruang. 2018. Spesifikasi Umum Bina Marga 2018 Revisi 1 Untuk Pekerjaan Jalan Dan Jembatan.

Nufriyanto, H. Kajian Campuran Panas Aspal Aggregat Asbuton Retona Blend 55 (Ac-Wc) Dan Aspal Pen 60/70 Dengan Pengujian Marshall. Jurusan Teknik Sipil, Fakultas Teknik Sipil dan Perencanaan, Institute Teknologi Padang.

Qodar, T. (2016). Pengaruh Penggunaan Serbuk Batu Kapur Putih Madura Sebagai Filler Padsa Campuran Aspal Panas (Hot Mix) Asphalt Concrete Wearing Course (AC-WC) Terhadap Karaktristik Marshall. Jurusan Teknik Sipil Fakultas Teknik Universitas Madura

Suryana,N, Susanto, I, Ronny,Y, Sembayang, IR. Evaluasi Kinerja Campuran Beraspal Dengan Bitumen Hasil Extraksi Penuh Dari Asbuton. Pusat Penelitian Dan Pengembangan Jalan Dan Jembatan
Kementrian Pekerjaan Umum Dan Perumahan Rakyat, Bandung.

Setiawan, A. (2017). Pengaruh Penggunaan Serbuk Batu Kapur Sebagai Filler Terhadap Karakteristik Uji Marshall Pada Campuran Aspal Panas (AC-WC). Jurusan Teknik Sipil Fakultas Teknik Universitas Madura.

Setiawan, A,dan Rahmat, R. (2011). Studi Penggunaan Asbuton Butir Pada Campuran Beton Aspal Binder Course (AC-BC). Jurnal Rekayasa Dan Manejemen Transportasi Volume 1 No. 2 Juli 2011 Hal.99 118. 